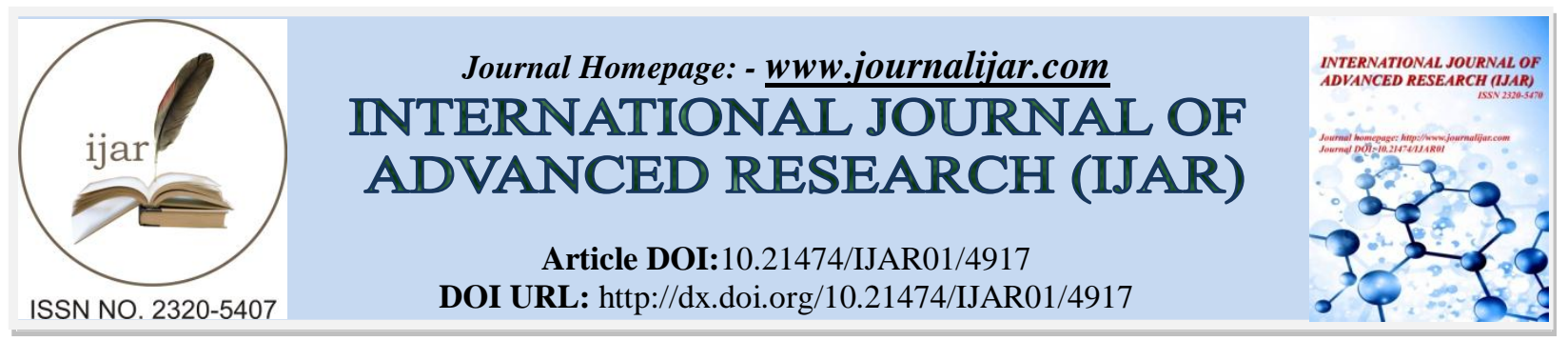

RESEARCH ARTICLE

\title{
THE FUTURE OF EXTENSION EDUCATION OFFERED BY THE UNIVERSITY OF ZAMBIA: A HYPOTHETICAL PERSPECTIVE USING EXISTING LITERATURE.
}

\author{
Davies Phiri ${ }^{1}$, Wanga Weluzani Chakanika ${ }^{2}$, Nyondwa Zulu ${ }^{3}$ and Tiwonge M. Zyambo ${ }^{4}$. \\ 1. Traditional Affairs Officer, Ministry of Chiefs and Traditional Affairs, Kazungula District, Zambia. \\ 2. Senior Lecturer, University of Zambia, DAEES. \\ 3. Part-Time Lecturer, University of Zambia, DAEES. \\ 4. Quality Asurance Officer, ZESCO Ltd. Zambia.
}

\section{Manuscript Info}

Manuscript History

Received: 22 May 2017

Final Accepted: 24 June 2017

Published: July 2017

\section{Abstract}

Predicting the future direction of Extension Education, offered by the University of Zambia, is neither a simple nor a straightforward topic, yet it is the focus of this article. The article reveals existing literature and draws such projections main from literature that focused on University of Zambia Extension Programmes. It is argued, in this article, that global pressure will lead to continuous alignment of University of Zambia extension education curriculum to meet the international standard. It assumes that University of Zambia will face stiff competition from mushrooming private universities in terms of quality and accessibility. The articles also presupposes that technology will impact on extension education in the future by creating, on one hand, easy access to literature and information by extension education stakeholders, and on the other hand, eroding extension curricular that are based on the cultural values of a specific locality. It is argued also in this article that changes in the employment sector will lead to changing learner needs which will result into increased partnerships between universities and industrial organizations. The article also highlights that University of Zambia, specifically the Department of Adult Education and Extension Studies (DAEES), will shift enrollment criteria to fit the needs of the current generation. This article also predicts a possible change in the original ideals to which extension education at the University of Zambia was founded.

Copy Right, IJAR, 2017,. All rights reserved.

\section{Introduction:-}

The future of extension education in Zambia is difficult to foresee. However, this article lays bare and predict certain trends that are likely to happen in a near future. Using existing literature, this article analyses certain changes that will continue sparking pressure on extension education in the near future. The paper will first start by defining what extension education is. A brief history of university extension education in Zambia will be given. Thereafter, the article will highlight major trends likely to happen. The article ends with a conclusion. 


\section{Meaning of Extension Education:-}

The concept of extension education has posed insoluble problems of definitions among scholars. This is partly because each scholar defines extension education in relation to their field of study and to a particular context. However, what seems to be common amongst scholars is the fact that extension education is developed to respond to the felt needs of the people and to solve their immediate challenges. For instance, Chakanika (1989:48)stipulates that "the centre is not a point where concepts are developed by experts in isolation and diffused to the periphery, rather, extension education is said to involve a two way channel of knowledge and experience in which, field problems find their way into the laboratories and results are in turn taken back to the farmers and villagers." He further suggests that a more fitting definition for extension education is the one put forward by Savile (1965), which stipulates that extension education is ".... a process of education, its constant aim being to develop the knowledge, the will power and the skill of the people to solve their own problems, by their own efforts, instead of waiting for government to do it for them" (Chakanika, 1989:47).

The forgoing view is also shared by Bradfield (1966:11) who states extension has been developed as the only logical, scientific and successful way of bringing knowledge to farmers to help them farm their lands more efficiently...,by developing the agricultural skills and knowledge of the farmers, enabling them to make more productive use of the country's natural resources

Robert, quoted by Jespon (1973:99) shares similar sentiments the author opines that the original purpose then of university extension movement was to create students, and to create them out of a new class to create students not merely from the well born and wealthy classes, but from the whole population out of the raw materials of masses... breaking down intellectual caste and the universal extension of the intellectual franchise. It meant education on the principles of the gospels.

From the above definitions, it can be noted that what seems to be agreeable among scholars is the fact that extension education signifies that type of education which is stretched out to the people beyond the limits of the educational institutions to which the formal type of education is normally confined. It can also be argued that the main objective of Extension Education is to provide education suitable to all classes in the community within which it operates. Important to note isthe fact that, this educational paradigm has the capacity to bridge the gaps left by the deficient Secondary and University formal education.

\section{Principles of Extension Education:-}

There are several ethics governing the general field of extension education. According to Chakanika, (1989: 49), the general principles of extension Education can be summarised as follows:

1. extension work should be based on felt needs and enlightened desire of the people;

2. it should be according to the local conditions of the people;

3. it should start with the people and work in harmony with their problems;

4. that there ought to be a democratic procedure in the formulation and execution of programs;

5. programs should be started with the simplest problems of the people and should be designed as to give greater benefit to the people and extension work should be made in consultation with the people.

From the aforesaid principles, it is apparent that the success of any extension program is dependent on the active participation of the community which it is intended to benefit. In other words, for any extension program to succeed, it should be action-oriented, involving the community, often with an illiterate majority; for the purpose of changing their attitude and mental outlook to bring about improvement (development) even in their standard of living. Its primary aim is to help rural people develop themselves, their community and the nation as a whole (Oomen-Myin, 1981). Extension programmes should therefore not be centralised. This entails that the aims, methods and content of extension education interventions should tally with the cultural values, norms and beliefs of a particular community. It is therefore, the learners or participants who have to formulate, accept and execute the program for their own improvement (Chakanika and Mtonga, 1995).

\section{Brief History of Extension Education at the University of Zambia:-}

Shortly after gaining political sovereignty in 1964, Zambia faced a bitter aftermath of that transition as it did not have well-trained technocrats to take over and run the affairs of the country. According to Carmody (2004), there were 961 individuals at independence known to have passed the Cambridge School Certificate (form v) against a population of 4 million adults. It was estimated that at Independence, there were 100 University graduates (GRZ 
1966). This proves the assertion that Zambia was less prepared to take over the running of the country owing to the fact that there were few educated people as compared to other African Countries (Nduna, 2010).

As a response to this challenge, the government embarked on a massive expansion of the education system. Firstly, by expanding the structures that were already in existence, such as, primary schools, secondary schools as well as colleges. Secondly by building new schools in districts where there was none (GRZ, 1966).

Furthermore, the Zambian Government realised the need to have a State University. This lead to the appointment of a Commission under the leadership of Sir Lockwood to advise on the development of a University. The Commission made recommendations on the establishment of a University in Lusaka. According to the Lockwood Report (1964), the establishment of the University had a two- fold conviction; first that the University must be responsive to the real needs of the country; secondly that it must be an institution which on merit will win the respect and proper recognition of the University world. Unless it satisfies these two criteria, it will fall short of meeting its national responsibility. Therefore, in 1966 the University of Zambia was opened with the aim of meeting the needs of the people of Zambia.

Owing to the fact that the establishment of the university was made possible by contributions from the general public, the government and academicians realised that universities are not institutions isolated from society, but are an integral part of it and therefore have responsibilities to society. This was an influence from the British style of University Education which was designed in such a manner that it was accessible by both traditional and nontradition students. As such, the Lockwood Report recommended that the University should not limit its services to internal students only but should extend its services even to people outside the University. It is this line of thought that lead to the establishment of the Department of Extra-Mural Studies and a Department of Correspondence Studies to be responsible for outreach programmes (Alexander, 1975). While the former, now called the Department of Adult Education and Extension Studies, was specifically responsible for the provision of Extension Education, the latter, now known as Institute of Distance Education, was task to provide Distance Education.

The Department of Extra-Mural Studies assumed the role of mobilising Zambia's available human resource to take part in national development. This was done by conveying the essence of the University's teaching to as many people as possible throughout the country. The functions laid down for the Department of Extra-Mural Studies in 1966 by the Senate included the provision of study which was of University nature to the general public; provision of training for adults; research into academic and adult education problems; and the teaching of subjects related to economic and social development with particular reference to the first national development plan(Alexander 1975:39). The Department of Extra-Mural Studies provided extension education to people throughout the country. However in the 1970's the Department of Extra-Mural Studies was merged with the Departments of Mass Communication, Adult Education and Correspondence Studies to become the Centre for Continuing Education. In the restructure the Department of Extra-Mural Studies became known as the Department of Extension Studies and Conferences (Nduna, 2010; Ngoma, 2009).

After 1994, extension programmes were placed under the custard of the Department of Adult Education and Extension Studies in the School of Education. This was after the restructuring of the Centre for Continuing Education by the University Senate. The Department of Correspondence Studies became the Directorate of Distance Education, the Department of Mass Communication moved to the school of Humanities and Social Sciences. The two remaining departments were moved to the School of Education and merged into the Department of Adult Education and Extension Studies (Ngoma and Nyirenda, 2005).

University extension education in Zambia has been applied through public lectures conducted for a mixed target group, through Theatre for Development which has been used in reaching the grass-roots level members of the society, through Seminars or workshops which cater for a broader clientele; and lastly University extension education has been applied through evening classes (Chakanika and Mtonga, 1995). Non-credit certificate courses have been taught in evening classes in all the centres in Zambia.

Since inception to 2009, Extension education at the University of Zambia did not include any senate approved course. This attracted criticism from both private and public employers, from students and from the general public. This motivated extension planners to assess the public need for credit courses. In 2002, a short study was undertaken and it was established that most students wanted the centres to run diploma courses. Specialists were identified to 
design the syllabi for diploma courses. Workshops were organized to discuss the syllabi and a decision was made on the course contents (Moonga, 2008). In 2009, Extension Studies Diploma courses started in all the centres throughout the country.

Future trends in extension education at the University of Zambia: projections:In the next few years, extension education, offered by the University of Zambia, is likely to change its scenario. The following are anticipated future trends that are likely to determine the direction of extension education.

\section{Curricula Alignment due to Globalisation:-}

In order to act globally in a competitive environment, the University of Zambia (UNZA), through the Department Adult Education and Extension Studies (DAEES), is likely to continue to aligning her curricular. Scott (1993) posited that as the number and variety of students increases, it will become more difficult for every university to maintain a common academic purpose, based on a set of intellectual assumptions which underlie all university courses, whatever the subject. The situation is predicted to be similar at the University of Zambia. This is due to the fact that most of the universities, UNZA inclusive, have and will continue to redesign or align their curriculum to support today's' students to fit globally. Those destined to adapt to a fast changing technological world will demand a curriculum that emphasises on information communication technology. Those who will form the cadres of experts that dominate employment in the most dynamic sectors of the economy, probably the largest group of tomorrow's graduates, will need to be drilled in high-grade technical and professional skills. Finally those who, either because they have been marginalized by the labour market will demand entrepreneurship skills (Scott, 1993).

Of equal importance to note is the fact that globalisation will also pose serious threats to the field of Extension Education at the University of Zambia. A well-known fact is that extension education in Zambia was established on the premise that it should be according to the local culture and local condition of a particular locality (Chakanika, 1989). However, globalisation has a potential to erode extension education Curricular that are based on the local conditions of the Zambian society. Power, (2000:152) observed a related danger by noting that globalisation brings with it a mix of opportunities and threats for every nation, culture and educational system. On the one hand, the removal of barriers and new technologies create new possibilities for intercultural exchange and dialogue, but on the other, we face the danger of a new global imperial regime in which one political, economic and communication culture is unilaterally favoured over all others.

The forgoing undertone confirms the fact that globalization will continue to call for curricular alignment in extension education. However, the connotation also warns players in the education sector to be alert to the dangers associated with global happenings.

\section{Continued competition with other Learning Institutions:-}

Another future trend that extension education at UNZA is likely to encounter stems competition from mushrooming local and international leaning institutions, as well as, other public learning institutions. The Highest qualification one can acquired from UNZA extension education programmes is a Diploma. However, there is a relatively a wellestablished group of private higher education sector in Zambia, offering diploma certificate, diploma and degree programmes, using flexible non-traditional systems such as distance learning and online learning programs. These are largely through franchise agreements with local and international Universities, as well as, under the institutions' own auspices.

The role that these growing public and private higher education sectors will play to shape access patterns in the coming years is not completely clear. However, certain trends emanating from this stiff competition among universities are predictable. It is highly evident that these mushrooming institutions of learning will create local and global competition for talent in top students, researchers and lecturers in Extension Education (Sarker, Davies and Tironis; n.d). For major players in Extension Education like the University of Zambia to compete at a world-class level in teaching and research, they will need to maintain higher standard of research so that they can be recognised internationally and can compete with other institutions by means of higher quality and higher standard of research. It is likely therefore, that institutions offering University of Zambia will, through DAEES, find that international and local collaboration with other educational institutions, industry, communities and government will be necessary to exploit the opportunities offered by globalisation (Sarker, Davis, and Tiropanis; n.d). 


\section{Adoption of emergent technologies:-}

Any predictions concerning the future of education are less likely to avoid an analysis of technological trends. There is greater evidence suggesting that extension education at UNZA will adapt to new technologies if it is to remain competitive in this fast changing technological world. The basic premise underlying this line of thought emanates from the current trend in UNZA Extension programmes where a compulsory computer course has been infused in the syllabus used for Lusaka District. This trend creates a possibility for a revision of required qualifications needed for tutors under extension programme.

Technological advancement will unearth both challenges and opportunities in the field of Extension Education at UNZA. One foreseeable possibility is that technologies, like internet and its associated innovation, will increase the capacity of an educator more quickly, easily and more scalable to help students make connections to content, context, and community, resulting in more powerful learning experience (Sarker, Davis, and Tiropanis; n.d). Eshiwani (1999) supports this connotation by starting that In 1996, the World Bank came up with the concept of the African Virtual University (AVU). AVU is a concept of distance education, which uses a technological mode of instructional delivery.... For the participating universities, the AVU project has helped to solve one of the major problems facing researchers and scholars in African universities: namely, lack of up-to-date journals and accessibility to information from other libraries. The digital library is a giant step forward for these universities. For example, Kenyatta University, in Kenya, where the AVU project first started, is currently able to access more than 1,700 journals through the AVU digital library, and this number is destined to grow to over 2,400 journals.

Such forces are likely to influence the activities and organization of Extension Education at UNZA. It is possible that the Department, responsible for extension education at UNZA, will adopt similar innovation for them to survive of this global pressure. Unless UNZA takes up this challenge, they face the prospect of becoming marginalized at an international level.

On the other hand, information and communication technologies will continue to accelerate the globalisation of cultural values. This will sharply contradict with one of the original ideals for extension education that it should be in congruence with the cultural values of the local nationals. As Omekwu (2006) reiterated, the internet is a key development in the growth of globalisation because globalization has changed the nature of national government imposing international culture on local culture. If these innovations are adopted without critical analysis of their possible risks, extension education risks being turn into an agent of neo-colonialism.

\section{Shifting admission priorities:-}

The growing demand for extension education will collide with forces limiting enrollment. This will result into shifting admission priorities and continued rise of costs needed to attend the programmes. Such changes will favour well-off, tuition-paying students and may keep low-income students from entering the programmes or from completing their courses. Diamond (2006) noted that while all education will bear fruit, we are creating a bifurcated system in which the best education will go to those who can pay for it.

Extension Education will turn into an easy backdoor root to lifelong learning and professional development. These programmes will tend to reduce the elitist nature of university admissions, and service broader and more diverse clienteles. However, a closer staring into the crystal ball suggests that mass entry by school-leavers is likely to complement and complicate the enrollment of working mature students. There is a risk that mature students will be stigmatised as deviant. This is due to the fact that most school leavers will most likely resort to this education paradigm as an alternative route to higher education which they cannot easily access in traditional institutions due to strict enrollment requirements, exorbitant fees and remoteness from formal institutions (Scott, 1993).

\section{Partnerships between Universities and Industrial or Businesses Sectors:-}

In a no distant future, employability will accelerate and dominate on the agenda of UNZA extension education courses of study. This is because workers seem likely to continue seeking educational opportunities to survive in the world of work (West, 1999). The central hypothesis underlying this argument stems from the fact that University Departments are being challenged to move from being involved with only community-based learning to a much broader spectrum of university provision which will respond more directly to labour market demands (UNESCO 1997).Such challenges suggest that even in the near future, Extension Education at UNZA will continue to restructured itself in order to "meet the needs of an increasingly technologically oriented economy; to deliver the requisite research, highly trained people, and knowledge to equip a developing society with the capacity to address 
national needs; and to participate in a rapidly changing and competitive global context. This requires the reconceptualization of the relationship between higher education and the state, civil society, and stakeholders, and among institutions" (Education White Paper 1997:10).

Another area where partnership will manifest is in the delivery of educational services. It is mostly likely that Departments responsible for Extension Education at UNZA will partner with media institutions to enable them advertise their services and provide e-learning or broadcast their lessons to the public. This is due to the fact that UNZA Extension Education Unit will face both external and internal pressure for e-learning and medial delivery of education services. One notable internal force will emanate from the UNZA Institute of Distance Education which has already partnered with Muvi Television to broadcast lessons to its clientele. This will likely to force the Extension Unit at UNZA to indulge in such partnerships

\section{Dominance of credit courses:-}

It is also anticipated that courses carrying credit value will dominate in the field of Extension Education in Zambia. There is some evidence that extension education will embrace mixed-discipline courses with much broader academic goals for intellectual more than for social reasons. The UNZAoriginal traditional non-credit courses may lose their old power in an increasingly issue-oriented and topic-related curriculum. This was cemented by Serpell (1993:12) who shared similar sentiments by cautioning that By offering such courses to older students without formal credentials, such have the potential to counteract the socially extractive tendencies of the elitist narrowing staircase model but if excessive emphasis is placed on formal certification, the courses are liable to be co-opted as back-door entry routes to the extractive and elitist model they were designed to counteract.

The above connotation is likely to be true in the near future. Non-credit courses risk fading if excessive emphasis will be of formal qualification. Already, there is some proof suggesting the extinction of non-credit courses in University of Zambia Extension Programmes. For example, the study by Nduna (2010) revealed that all the extension education courses provide in North Western Province of Zambia where senate approved leading to either certificate or diploma and that no student was enrolled in any non-credit course. In a similar instance, Moonga (2008) observed that enrollment levels for credit based courses had increased than those of non-credit interventions as the former have proved to be popular than the latter.

\section{Forces Emanating from Research Studies in Extension Education:-}

There is some evidence suggesting that research studies specifically on Extension Education will continued to flareup in Zambia. These studies will come with them certain recommendations that will continue to call for adjustments on policies and structures of extension education programmmes. For example, credit based courses where infused into UNZA Extension Education after a research was conducted to determine public demand for such courses (Moonga, 2008). This will continue even more in the future than before.

\section{Conclusion:-}

The main thesis for this article has been the prediction of the future of extension education at the University of Zambia. The article has highlighted that globalization and technology will have an influence in the management, organization and delivery of extension programmmes. It has shown how competition among providers of higher education will influence the direction of extension of education. The article has also indicated how emerging issues in the employment sector and general environment will continue to spark pressure on extension education managers for readjustments of curricular content. The article has also provided the challenges and opportunities created by these forces on extension.

\section{References:-}

1. Alexander, D. (1975). Origins and Development of University Extension in Zambia. Occasional paper No.3. Unpublished

2. Bradfield, B.J. (1966). Guide to Extension Training. Food and Agriculture Organisation of United Nations: Rome.

3. Carmody,B. (2004). The Evolution of Education in Zambia. Lusaka: Bookworld Publishers.

4. Diamond, R. M. (2006)."Why Colleges Are So Hard to Change." Retrieved on Oct. 15, 2006, from http://www.insidehighered.com/views/2006/09/08/diamond. 
5. Chakanika, W.W. and Mtonga, H. (1995). "Constraints in University Extension Work in Zambia: The Experience of two Resident Tutors." International Journal of University Adult Education. V. XXIV. (1): $42-49$

6. Chakanika,W.W. (1989). "A Critique of Extension Work in Zambia." International Journal of University Adult Education. V. xxviii (2):47-56.

7. Education White Paper (1997). Programme for the transformation of higher education. Pretoria: Department of Education.

8. Eshiwani, G.S. (1999). "Higher Education in Africa: Challenges and Strategies for the 21st Century."In P.G. Altbach and P.M. Peterson. (eds)(1999).Higher Education in the 21st Century: Global Challenge and National Response. Boston: Boston College Center for International Higher Education, pp.31-38.

9. GRZ (1966).Ministry of Education Annual Report. Lusaka: Government Printers.

10. Jepson, N. (1973). The Beginning of English University Adult Education, Policy \& Problems. London: Michael and Joseph Limited

11. Lockwood Report, (1963).Report of the Development of a University in Northern Rhodesia. Lusaka: Government Printers.

12. Moonga, A.H.L. (2008). The Evolution of University Extension Studies in the University of Zambia. A paper presented at the Workshop of Resident Lecturers and Auditors in Siavonga. (Unpublished).

13. Nduna, M. (2010). Challenges Encountered by the University of Zambia in the Implementation of University Extension Education: A Case of North Western Province. A Dissertation Submitted To The University Of Zambia In Partial Fulfillment Of The Requirement For The Award Of The Degree Of Master Of Education. (Adult Education)

14. Ngoma, P. S., Nyirenda, H. B. C. (2005). A Round Peg in a Square Hole: The Case of the Department of Adult Education and Extension Studies in the School of Education University of Zambia. Lusaka: University of Zambia Press

15. Ngoma, F. (2009). "A Review of Factors Which Influence Learner Participation in University Extension Education in Chipata District." A dissertation submitted to the University of Zambia in partial fulfillment of the requirement for the award of the degree of master of Education (Adult Education)

16. Power, C.N. (2000). “Global Trends in Education.”International Education Journal V.1 (3): 152-163

17. Sarker, F., Davis, H., and Tiropanis, T. (n.d). A Review of Higher Education Challenges and Data Infrastructure Responses. Southampton: University of Southampton

18. Scott, P. (1993). The Idea of the University in the 21st Century: A British Perspective. British Journal of Educational Studies, V. 41(1):4-25

19. Serpell, R. (1993). The Significance of Schooling: Life -Journeys in African Society. Cambridge: Cambridge University Press

20. Omekwu, C.O. (2006). "African Culture and Libraries: Information Technology Challenges." Electronic Library, V.24 (2):247-248

21. Oomen-Myin, M.A (1981). Involvement of Rural Women in Village Development in Tanzania: A case Study in Morogoro District. University of Dar-es-Salam: Monogoro.

22. UNESCO (1997).Universities and the future of adult learning. Hamburg: UNESCO

23. West, G.B. (1999), "Teaching and Technology in Higher Education: Changes and Challenges."Journal article of Adult Learning, V. 10 (4): 16-17. 